\title{
Perancangan dan Penataan Kawasan di Sepanjang Sungai Banjir Kanal Timur Kelurahan Bugangan dan Kelurahan Rejosari dengan Konsep Livable Riverfront Settlement Kecamatan Semarang TImur, Kota Semarang
}

\author{
Design and arrangement of the area along the Eastern Canal Flood in \\ bugangan and Rejosari Villages with Livable Riverfornt Settlement \\ concept, East of Semarang subdistrict, Semarang
}

\author{
R.D.A. Puteri, R.S. Pulungan, H.D. Tambunan, H.M. Rahmi, R. Amalia, A.R. \\ Davinaldo, M.W. Hidayat, M. Mazz, D.D. Febriani, Z. Zulhamdi, H. Sima*
}

${ }^{a}$ Departemen Perencanaan Wilayah dan Kota Universitas Diponegoro, Semarang, Indonesia

\begin{abstract}
Abstrak
Livable Riverfront Settlement merupakan suatu konsep perancangan yang memperhatikan livability lingkungan perumahan yang berada di kawasan dekat sungai. Konsep Liveable Riverfront Settlement merupakan turunan dari konsep perencanaan kawasan makro Sustainable Riverfront Settlement dan konsep perencanaan kawasan meso Ecological Riverfront Settlement. Tujuan dari penulisan ini difokuskan pada arahan perancangan permukiman sepanjanng banjir kanal timur Kelurahan Bugangan dan Kelurahan Rejosari yang memiliki permasalahan yaitu terdapat permukiman kumuh dan permukiman liar, terjadinya banjir, minimnya open space, rendahnya kualitas lingkungan hidup dan terjadi backlog perumahan. Dalam penulisan ini menggunakan metode kuantitatif dengan teknik analisis deskriptif, dan metode kualitatif dengan wawancara dan observasi lapangan. Hasil dari identifikasi dan analisis arahan perancangan (UDGL) permukiman permukiman sepanjanng banjir kanal timur. Kelurahan Bugangan dan Kelurahan Rejosari berdasarkan 3 indikator yaitu peningkatan perekonomian melalui penyediaan lapangan pekerjaan (job creation), pengelolaan resiko bencana banjir melalui perbaikan kualitas lingkungan (disaster risk management), serta penyediaan perumahan yang layak huni dan terjangkau (livable housing provision).
\end{abstract}

Kata kunci: Permukiman, Banjir Kanal Timur, Livable Riverfront Settlement

\begin{abstract}
Livable Riverfront Settlement is a concept design that is mindful of environmental livability housing which is in the nearby river. The concept of Liveable Riverfront Settlement is a derivative of the concept of macro-regions planning Sustainable Riverfront Settlement and the concept of the planning area of meso Ecological Riverfront Settlement. The purpose of this writing is focused on the design of landing neighborhood along the Eastern Canal flood in Bugangan and Rejosari village who have a problem like slums and squatters settlement, the occurrence of floods, the lack of open space, the low quality of the environment and housing backlog.In this article using quantitative methods with descriptive analysis techniques, and the qualitative method with interviews and observations of the field. The results of the identification and analysis of the design of landing (UDGL) settlement along the Eastern Canal flood in Bugangan and Rejosari village based on 3 indicators, the improvement of the economy through the provision of employment (job creation), the management of flood risks through the improvement of environmental quality (disaster risk management), as well as the provision of housing that is affordable and livable (livable housing provision).
\end{abstract}

Keyword: Housing; Banjir Kanal timur; Livable Riverfront Settlement

\footnotetext{
* Corresponding author. Author's Name.

E-mail address: lab.rancang@pwk.undip.ac.id
} 


\section{Pendahuluan}

Perancangan kota (Urban Design) pertama kali berkembang di negara-negara maju seperti Eropa Barat dan Amerika. Shirvani, (1985) mengatakan bahwa perancangan kota (urban design) merupakan kelanjutan dari perencanaan kota (urban planning) sebab bagaimana hasil perencanaan kota belum dapat dapat dilaksanakan tanpa ada rancangan desain dari rencana yang telah disusun. Dari pengertian tersebut dapat dikatakan bahwa perancangan kota (urban design) memiliki tekanan pada penataan aspek lingkungan fisik kota yang terlihat secara fisual yang dibuat dalam suatu model. Dalam perencanaanya arah pengembangan kawasan perancangan akan menggunakan konsep Livable Riverfront Settlement yang menekankan pada 3 prinsip yaitu peningkatan perekonomian melalui penyediaan lapangan pekerjaan (job creation), pengelolaan resiko bencana banjir melalui perbaikan kualitas lingkungan (disaster risk management), serta penyediaan perumahan yang layak huni dan terjangka (livable housing provision).

Lokasi perancangan berada di Kelurahan Bugangan dan Kelurahan Rejosari dengan luas $\pm 22,3$ ha. Kelurahan Bugangan dan Kelurahan Rejosari merupakan kawasan dengan permukiman padat yang diapit oleh dua aliran sungai yaitu Sungai BKT di sebelah timur dan Kali Banger di sebelah barat. Sebalah timur kelurahan Bugangan terdapat kawasan perdagangan dan jasa tepatnya di J1 Barito Sungai BKT. Berdasarkan RTRW Kota Semarang kawasan perancangan Kelurahan Bugangan dan Kelurahan Rejosari juga termasuk dalam kawasan pusat kota yang diperuntukkan sebagai daerah permukiman dengan pengembangan bangunan vertical (rumah susun atau apartemen).

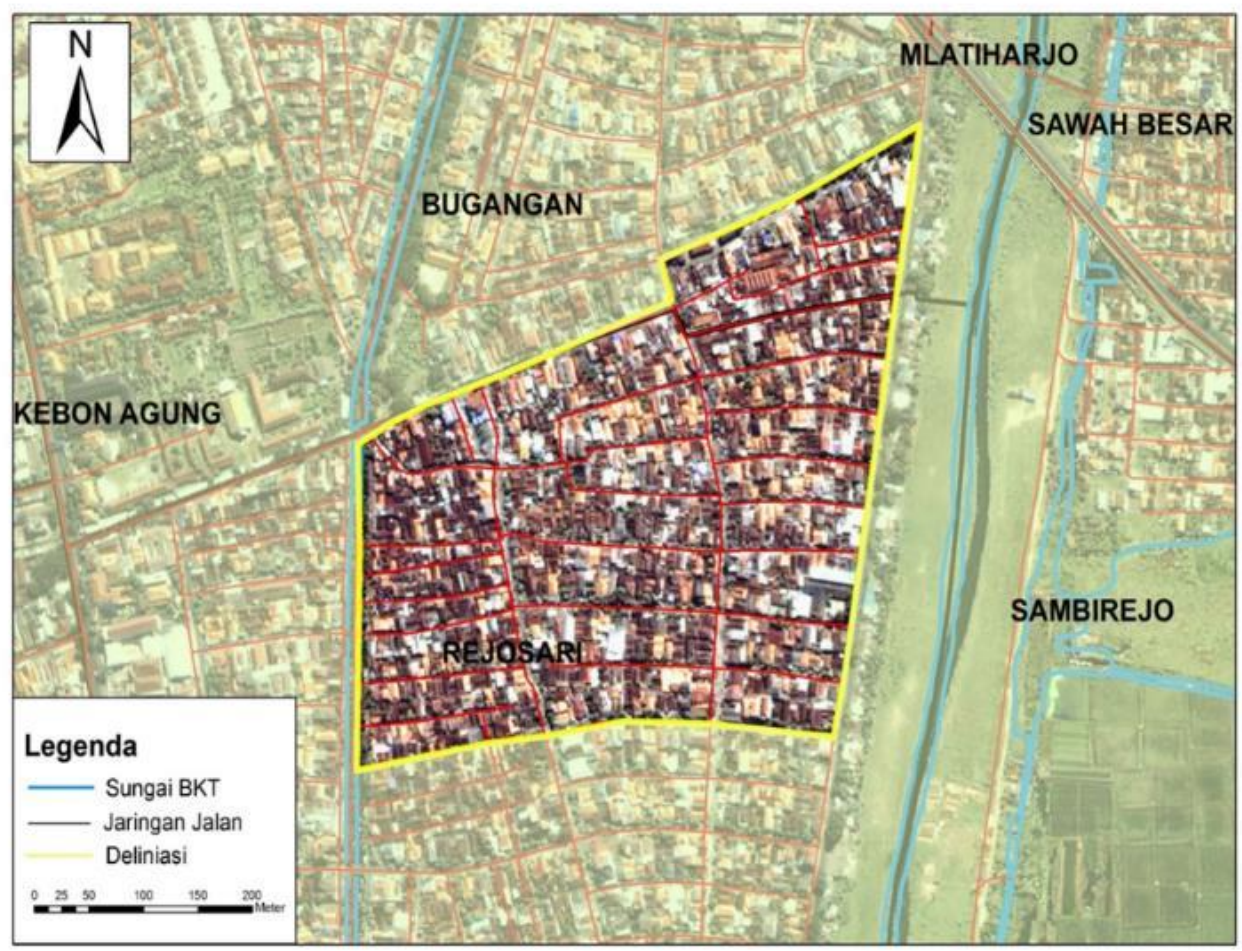

Gambar 1. Peta Deliniasi Kawasan Perancangan (Analisis Penulis, 2017)

\section{Kajian literatur}

Konsep Livable Riverfront Settlement merupakan suatu konsep perancangan yang memperhatikan livability lingkungan perumahan yang berada di kawasan dekat sungai. Livable Riverfront Settlement merupakan gabungan dari Waterfront City dan Livability. Teori Waterfront City pada dasarnya merupakan pembangunan pantai terpadu yang meliputi pembenahan, penataan dan pembangunan pantai, Hal yang diperhatikan dalam waterfront city menurut Srinivas 2003 dalam Rahmawati \& Rahardjo, (2016) yaitu infrastruktur hijau sekitar sungai sarana transportasi air, pengelolaan sungai, peningkatan akses jalan, jalur hijau zona penyangga, ruang terbuka hijau, dan kemudahan akses menuju sungai. 
Sedangkan, menurut Lennard, (1997) prinsip dasar untuk Livability adalah tersedianya berbagai kebutuhan dasar masyarakat, tersedianya berbagai fasilitas umum dan fasilitas sosial, tersedianya ruang dan tempat publik untuk bersosialisasi dan berinteraksi, keamanan, mendukung fungsi ekonomi, sosial dan budaya serta sanitasi lingkungan dan keindahan lingkungan fisik. Jadi, konsep livable riverfrornt settlement ini didasarkan pada beberapa indikator diantaranya kemudahan aksesibilitas, keberadaan perumahan yang layak huni dan terjangkau, peningkatan perekonomian, serta peningkatkan kualitas lingkungan.

\section{Konsep Mikro Keterkaitan Terhadap Konsep Makro Dan Meso}

Dengan pertimbangan aturan, permasalahan dan potensi yang ada di lokasi perancangan digunakan konsep Liveable Riverfront Settlement. Dari konsep makro Sustainable Waterfront Settlement dan mikro Ecological Riverfront Settlement diambil beberapa indikator diantaranya economy (job creation) dan ecology (disaster risk management) (Jaya, 2004). Untuk mengatasi masalah permukiman di wilayah studi ditambahkan indikator livable housing provision.

Pemilihan indikator disaster risk management guna mengembalikan fungsi alamiah sungai BKT agar dapat mengatasi masalah banjir. Selanjutnya indikator job creation yang diterapkan dengan peningkatan aktivitas ekonomi khususnya dengan penyediaan ruang untuk pasar lingkungan di Kelurahan Bugangan. Untuk penyediaan rumah layak huni ditambahkan dengan indikator livable housing provision. Dengan ketiga konsep yang akan diterapkan pada kawasan perancangan diharapkan dapat mengatasi permasalahan yang ada di kawasan perancangan baik permasalahan sekarang maupun yang akan datang. Berikut bagan konsep dalam mengatasi permasalahan - permasalahan yang ada sebagai berikut :

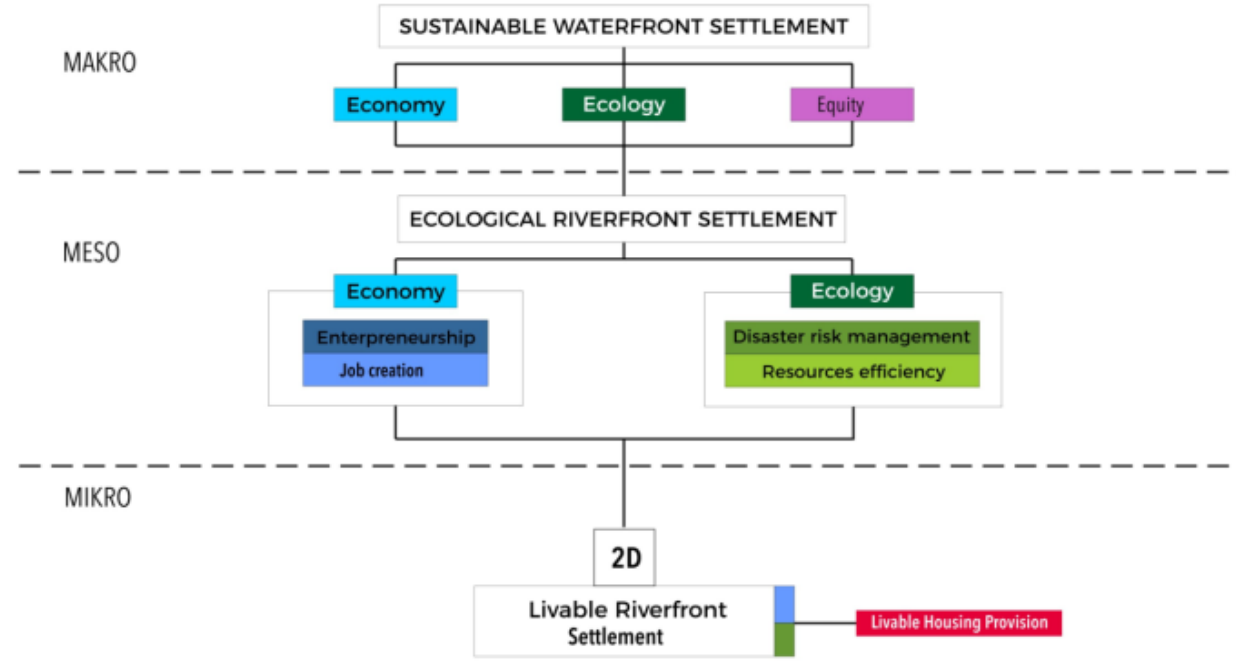

Gambar 2. Keterkaitan Konsep Perancangan Makro. Meso, dan Mikro (Analisis Penulis, 2017)

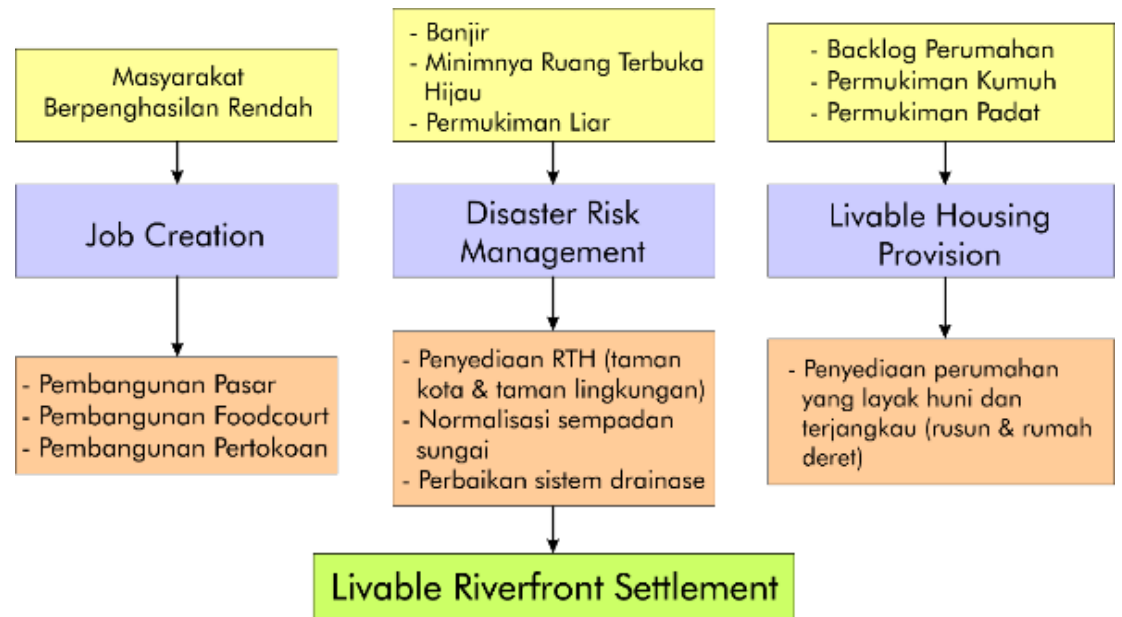

Gambar 3. Diagram Konsep Mikro (Analisis Penulis, 2017) 


\section{Hasil dan Pembahasan}

\subsection{Analisis Aktivitas, Pengguna, Kebutuhan Ruang dan Organisasi Ruang}

Pada kawasan perancangan, penduduk akan dikelompokkan menjadi tiga kelompok berdasarkan luasan rumahnya saat ini. Untuk kelompok penduduk dengan luas hunian antara 16 $\mathrm{m} 2-36 \mathrm{~m} 2$ dipindahkan ke rumah susun. Untuk luas hunian berkisar antara $37 \mathrm{~m} 2-60 \mathrm{~m} 2$ akan dipindahkan ke rumah tapak menengah berupa rumah deret bertingkat. Sedangkan, untuk rumah mewah yang berada di Jalan Cilosari akan dipertahankan sebagaimana kondisinya saat ini. Total penggunaan lahan ruang terbangun adalah $110.966 \mathrm{~m} 2$ dengan sirkulasi $30 \%$ dari total lahan ruang terbangun. Jadi total penggunaan lahan ruang terbangun ditambah sirkulasi adalah seluas $144255.8 \mathrm{~m} 2$ sedangkan total penggunaan lahan ruang non terbangun adalah seluas $81.450 \mathrm{~m} 2$.

Pada lokasi perancangan ada 3 (tiga) aktivitas yang akan diterapkan yaitu aktivitas utama, penunjang dan aktivitas pelayanan. Aktivitas utama pada lokasi perancangan adalah fungsi hunian. Berdasarkan hasil perhitungan, carrying capacity dalam kawasan perancangan seluas 22,3 hektar didapat sebesar 10.920 jiwa (2.184 KK). Jumlah penduduk eksisting di lokasi perancangan adalah $1.174 \mathrm{KK}$ yang terdiri atas 4.133 jiwa. Untuk pengguna kawasan tidak diproyeksikan karena pada lokasi perancangan sudah sangat padat sehingga penyediaan perumahan diutamakan untuk penduduk eksisting saja.

Dari analisis aktivitas, pengguna dan kebutuhan ruang didapatlah suatu organisasi ruang yang mengorganisir letak aktivitas dalam kawasan yang disesuaikan dengan karakter tiap ruang sehingga dapat berintegrasi dengan baik. Berikut merupakan organisasi ruang lokasi kawasan perancangan. Berikut merupakan organisasi ruang lokasi perancangan:

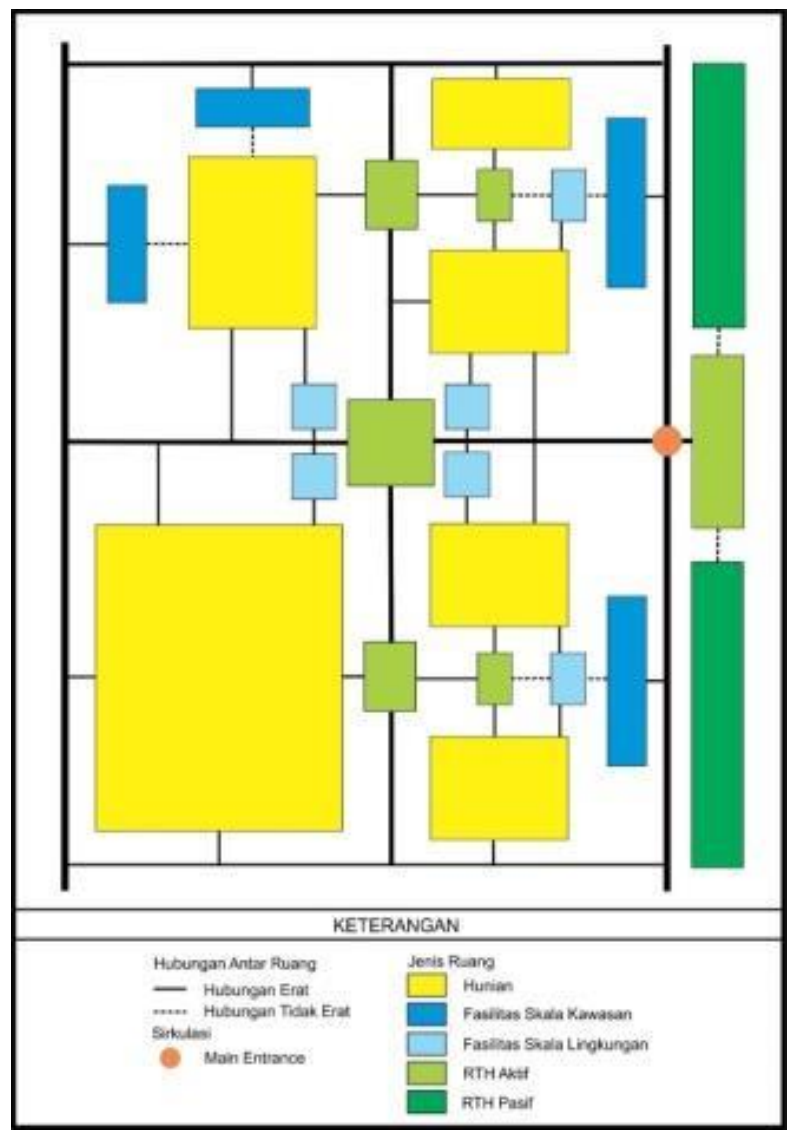

Gambar 4. Organisasi Ruang (Analisis Penulis, 2017) 


\subsection{Analisis Tapak}

Dalam analisis tapak terdapat beberapa komponen yang di analisis yang pada akhirnya menghasilkan zoning kawasan yang diperuntukan untuk menentukan penyusunan ruang di kawasan perancangan. Berikut analisis tapak kawasan perancangan.

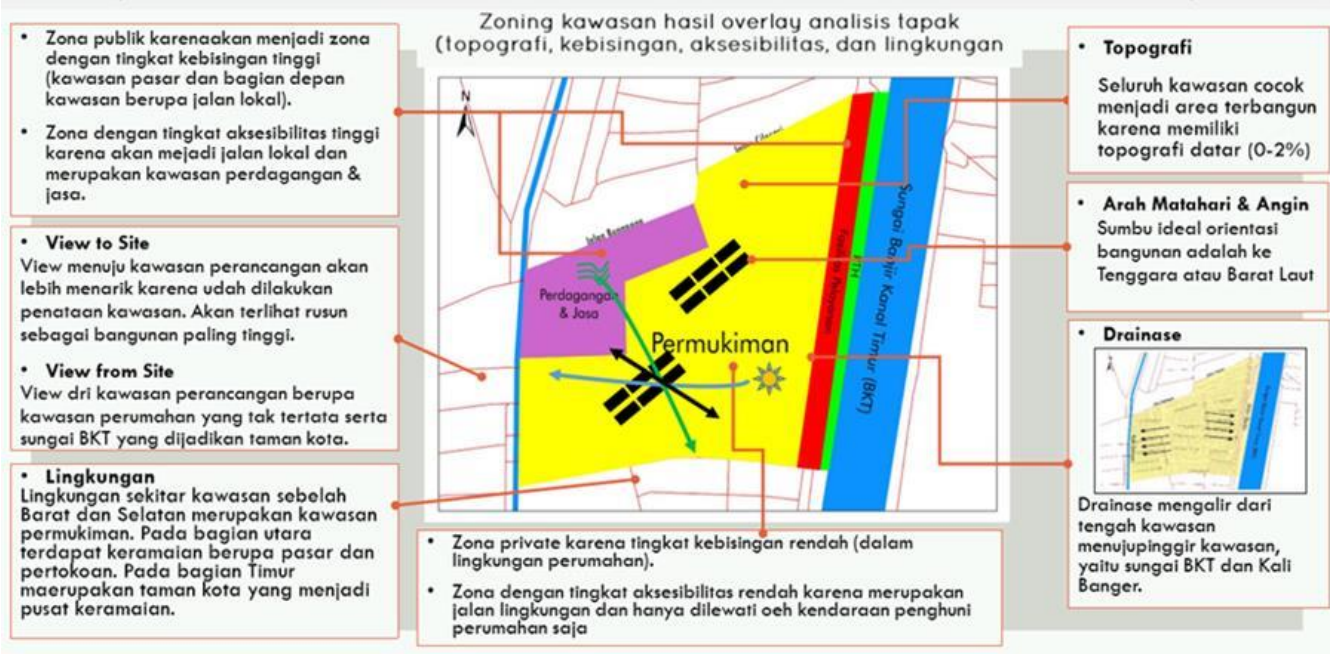

Gambar 5. Analisis Zoning Kawasan (Analisis Penulis, 2017)

\subsection{Analisis Infrastruktur}

Pada analisis infrastruktur ini membahas tentang arahan penataan infrastruktur di kawasan perancangan sesuai dengan teori dan kebutuhan yang ada pada lokasi perancangan. Berikut dibawah ini merupakan analisis infrastruktur dikawasan perancangan :

Tabel 1. Analisis Infrastruktur Kawasan (Analisis Penulis, 2017)

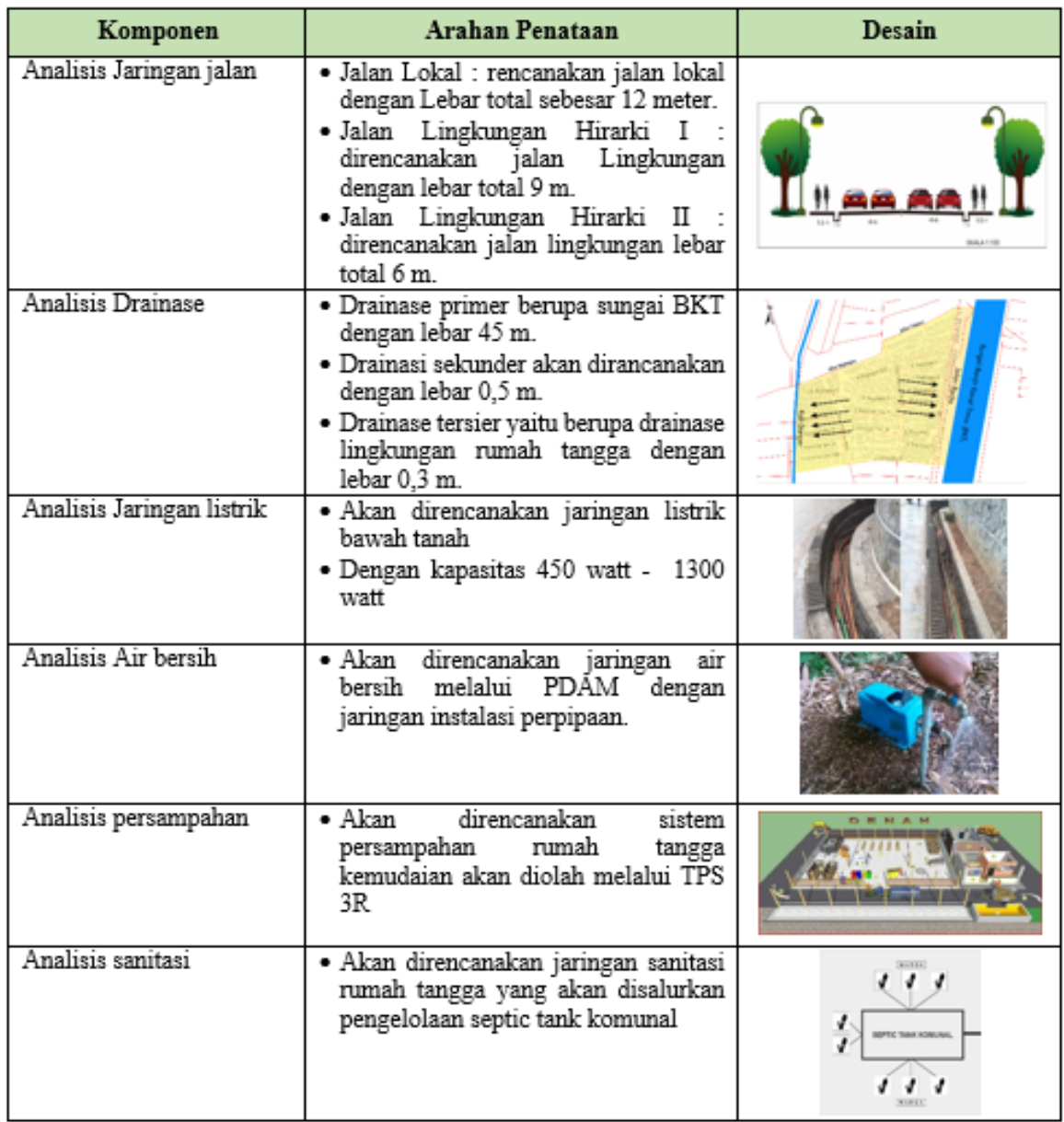




\subsection{Analisis Kriteria Terukur}

Menghasilkan KDB 70\%, KLB maksimal 6 lantai (asumsi 1 lantai 4 meter) namun yang digunakan pada hunian 1-2 lantai dan rusun 5 lantai. Jarak antar bangunan adalah 6 -8 meter untuk hunian dan 10 meter untuk rusun. Garis sempadan bangunan jalan lokal - lingkungan I adalah 12,98 $\mathrm{m}$ dan jalan lingkungan I -lingkungan II : 5,99 m.

\subsection{Analisis Kriteria Tak Terukur}

Access, Akses masuk ke kawasan perancangan dapat melewati jalan RA Kartini lalu ke Jalan Barito. Akan dibangun pedestrian untuk memberikan kenyamanan dan keamanan bagi pejalan kaki pada jalan lokal dan lingkungan I. Akan dilakukan pelebaran jalan lingkunan I selebar 9 meter dan jalan lingkungan II selebar 6 meter untuk memudahkan akses keluar-masuk kendaraan roda empat seperti mobil dan kendaraan pemadam kebakaran. Compatibility, Dengan topografi datar 0-2\%, direncanakan kawasan permukiman dengan bangunan rumah masyarakat yang memiliki bentuk yang seragam sehingga menimbulkan estetika yang indah. Kondisi topografi yang datar memungkinkan untuk pembangunan rusun 5 lantai. View, View to site adalah view taman kota yang berada di samping sungai BKT. View from site yang dapat dilihat adalah sungai BKT. Identity, Akan dibuat ruang terbuka hijau berupa taman kota di samping sungai BKT dan dibuat monumen tugu logam sebagai identitas kawasan. Sense, Penambahan RTH berupa taman kota, taman lingkungan, taman privat di tiap rumah masyarakat serta jalur hijau memberikan kesan permukiman yang asri, rindang dan nyaman. Livability, Penyediaan rumah susun, gedung pasar, ruang terbuka hijau berupa taman kota, penyediaan fasilitas berupa puskesmas, TK, SD, foodcourt dan peningkatan prasarana permukiman seperti perbaikan jaringan drainase dan air bersih untuk meningkatkan kenyaman masyarakat.

\subsection{Analisis Perancangan Kota}

Sirkulasi dan Parkir, Pada jalan lingkungan I dan jalan lingkungan II dirancang sirkulasi dengan dua arah. Direncanakan juga penyediaan ruang parkir baru yaitu parkir untuk melayani area Pasar Regol dan parkir untuk melayani pertokoan sebagai usaha yang sukses dalam perancangan kota. Pedestrian Ways memliki lebar 1,5 m pada lingkungan I dan jalan utama Barito. Direncanakan jalur pejalan kaki yang lebih tinggi dari badan jalan agar pejalan kaki dapat aman dari kendaraan bermotor. Ruang Terbuka Direncanakan taman kota di sepanjang sungai BKT yang dilengkapi dengan gazebo. Direncanakan juga jogging track dengan pepohonan di sepanjang pedestrian ways. Signage pada kawasan perancangan akan dilengkapi dengan rambu-rambu lalu lintas agar menghidupkan street space, penanda pasar sebagai penanda adanya Pasar Regol di kawasan perancangan. Pendukung Aktifitas Akan dibangun foodcourt, perpustakaan dan taman baca, Balai RW, relokasi puskesmas dan sarana peribatan berupa masjid, musholla, dan gereja, serta pedestrian sebagai jalur pejalan kaki.

\subsection{Analisis Elemen Estetika}

Sumbu yang terbentuk menghubungkan sub-sub pusat taman yang diakhiri dengan sebuah vocal point atau pusat aktivitas di tengah kawasan. Skala dan Proporsi, Desain bangunan dibangun menggunakan skala manusia. Proporsi kawasan terbangun adalah $70 \%$ KDB dan RTH 30\%. Rumah susun dibangun 5 lantai, rumah deret, pertokoan dibangun 2 lantai. Irama, Akan dirancang rumah susun sebagai bangunan paling tinggi yaitu dengan ketinggian $20 \mathrm{~m}$, rumah deret,pertokoan ketinggian 8 meter, dan perkantoran dengan ketinggian 4 meter. Hirarki, Pada kawasan rancangan, hirarki tertinggi adalah kawasan permukiman khususnya Rusun. Hal tesebut dikarenakan rusun memiliki bentuk dan massa bangunan yang lebih mencolok dibandingkan bangunan yang lain. Balance, Keseimbangan terlihat dari rumah deret yang memiliki ketinggian, bentuk dan masa bangunan yang sama. Konteks \& Kontras, Kontras terlihat pada perbedaan ketinggian hunian rusun $20 \mathrm{~m}$ sedang di sekelilingnya hunian landed dengan tinggi sekitar 4-8 $\mathrm{m}$. 


\subsection{Analisis Citra Kota}

Path. Berupa Jalan Barito, Jalan Cilosari, dan Jalan Kanalsari sebagai jalur utama yang menghubungkan antara kawasan perdagangan. Adapun jalur pedestrian berada di sepanjang Jalan Barito, Jalan Cilosari, dan Jalan Kanalsari yang berfungsi sebagai jalur sirkulasi bagi pejalan kaki . Edge antara kawasan berupa jalur hijau. Sedangkan, untuk edge yang membatasi kawasan rusun dengan Kali Banger berupa jalan lokal dan jalur hijau dengan vegetasi pohon kemuning. District berupa kawasan permukiman terdiri dari hunian mewah, menengah, dan rumah susun. Selain itu akan terdapat kawasan perdagangan berupa pasar dan pertokoan. Nodes berupa taman aktif di sekitar permukiman yang menjadi pusat aktivitas warga yang bermukim. Landmark. Landmark dalam kawasan perancangan terletak pada taman aktif di tengah permukiman berupa tugu logam yang dikelilingi air mancur.

\subsection{Urban Design Guide Line}

Tabel 2. Urban Design Guide Lines (Analisis Penulis, 2017)

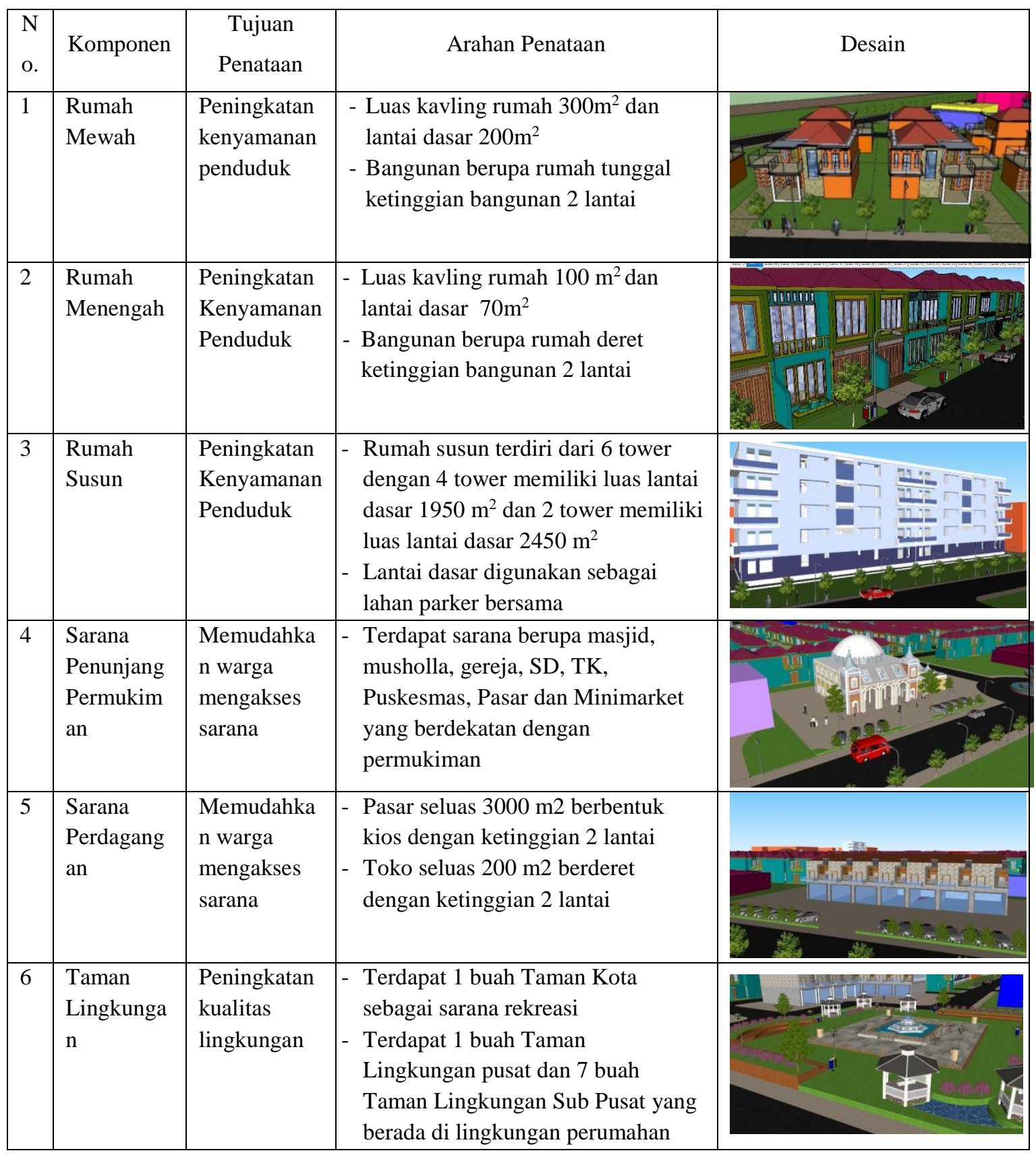




\subsection{Logical Framework}

Logical framework digunakan sebagai management tools untuk perencanaan, penilaian, serta monitoring dan evaluasi. Perencanaan program memiliki tujuan yaitu mengembalikan fungsi sungai dan mewujudkan permukiman yang livable pada tahun 2027 serta mewujudkan permukiman dengan sarana prasarana yang memadai dan lingkungan yang livable pada tahun 2037 di Kelurahan Rejosari dan Bugangan. Untuk mencapai tujuan tersebut diperlukan input berupa pengadaan lahan, dana, pengadaan tenaga kerja dan pengadaan kerjasama dengan pihak pemerintah, swasta, dan PCP dalam pengembangan kawasan. Input diatas akan menghasilkan output berupa:

a) Pengembalian fungsi sungai $\rightarrow$ normalisasi sungai, pembangunan kawasan resapan air, pembangunan taman kota.

b) Penyediaan permukiman yang layak huni $\rightarrow$ penyediaan permukiman berupa rusun dan rumah deret sederhana.

c) Penyediaan sarana dan prasarana yang memadai $\rightarrow$ penyediaan sarana penunjang permukiman.

d) Peningkatan kualitas lingkungan. $\rightarrow$ Penambahan jumlah RTH (taman kota,taman lingkungan pusat dan sub pusat).

Keterkaitan antara purpose, input, dan output akan mencapai goals yaitu mewujudkan kawasan permukiman tepi sungai melalui konsep Livable Riverfront Settlement di Kelurahan Rejosari dan Bugangan pada tahun 2037.

\subsection{Critical Path Method dan Network Planning Analysis}

Tahapan konstruksi dibagi menjadi 3 tahap. Tahap pertama adalah pembangunan rusun, pasar, pertokoan serta beberapa rumah. Tahap kedua pembangunan rumah deret dan sarana prasarana. Tahap ketiga adalah pembangunan rumah tahap 3 serta fasilitas penunjang lainnya

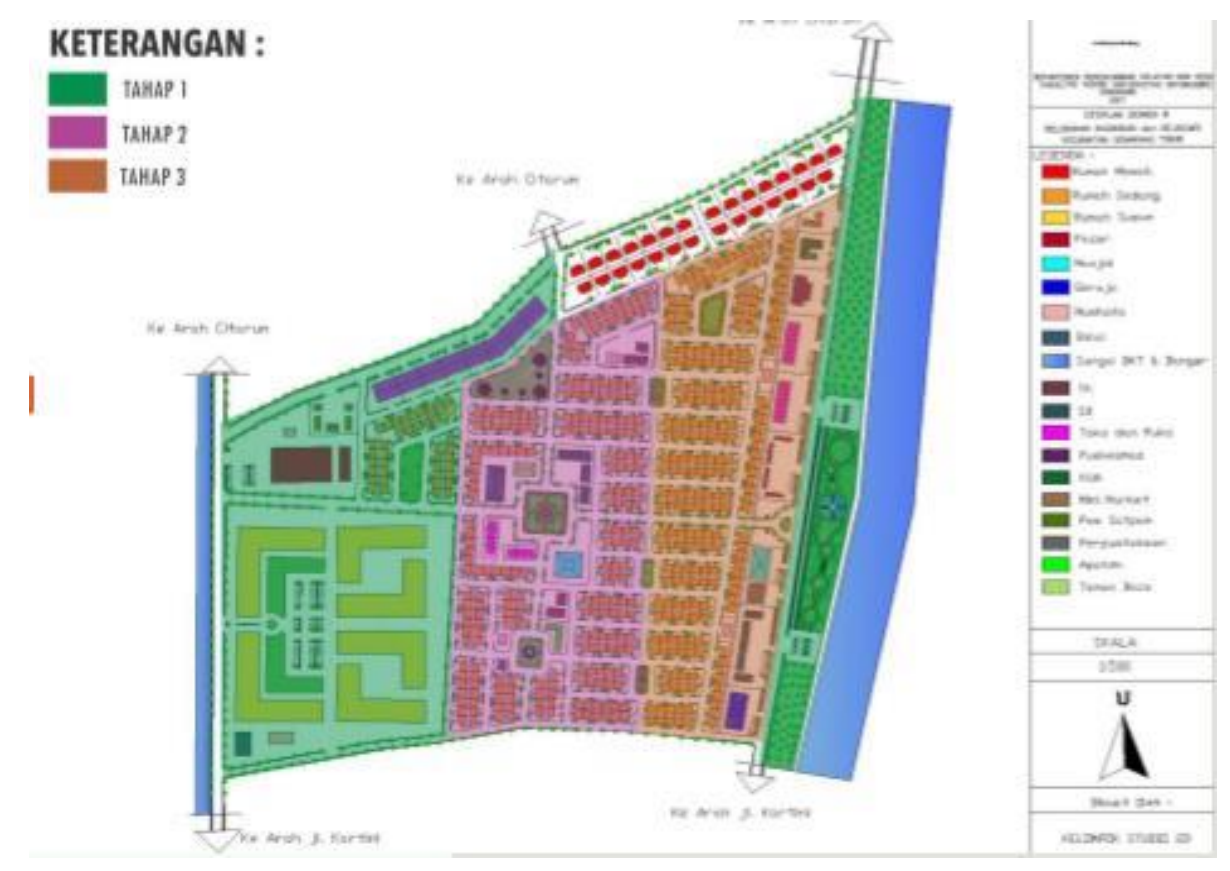

Gambar 6. Peta Tahapan Pembebasan Lahan dan Konstruksi (Analisis Penulis, 2017) 


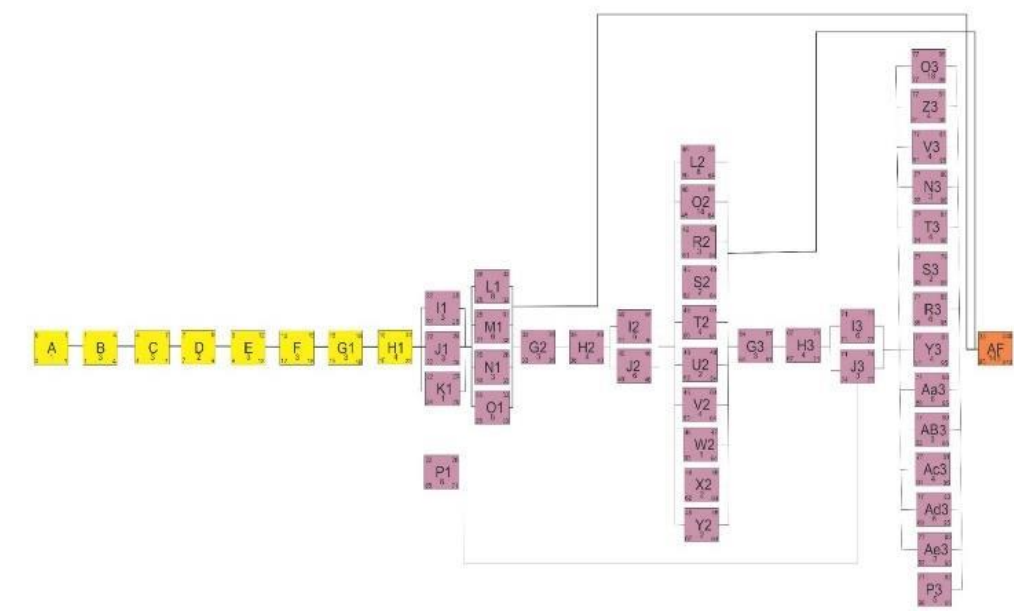

Gambar 7. Critical Path Method (Analisis Penulis, 2017)

\subsection{Manajemen Pengelolaan}

Adapun bentuk kerjasama dalam kawasan perancangan terbagi menjadi tiga penanggung jawab yaitu pemerintah, swasta, dan PCP.

- Konsep Manajemen Pengelolaan Pemerintah

Pemerintah bertanggung jawab dalam pembangunan dan pengelolaan rumah susun, taman kota, sekolah dasar dan sarana prasarana lainnya. Pemilihan manajemen pengelolaan oleh pemerintah karena kawasan tersebut dibangun untuk memberikan fungsi pelayanan kepada MBR sehingga retribusi yang dikumpulkan setiap bulannya ditujukan untuk biaya pengelolaan dan operasional dari sarana prasarana.

- Konsep Manajemen Pengelolaan oleh Swasta

Manajemen pengelolaan swasta yaitu dana, pengoperasian proyek, operasional proyek, dan pemeliharaan proyek berasal dari swasta seperti pembangunan minimarket, pertokoan, apotek, dan foodcourt. Keuntungan yang berasal dari operasional sepenuhnya dikelola dan dimiliki oleh swasta

- Konsep Manajemen Pengelolaan PCP

Pengelolaan PCP ialah bentuk kerjasama antara pemerintah dengan masyarakat. Pada kerjasama ini, dana berasal dari pemerintah dan masyarakat serta lahan berasal dari masyarakat. Bentuk kerjasama PCP dipilih karena dapat merealisasikan bentuk peremajaan kawasan lingkungan perumahan di kawasan perancangan terutama dalam pembangunan rumah deret.

\subsection{Pembiayaan}

Pembiayaan dihitung berdasarkan analisis kelayakan ekonomi dan finansial sesuai bentuk kerjasama pengelolanya dengan tingkat suku bunga $7 \%$.

- Pemerintah

\begin{tabular}{lll}
\multicolumn{1}{c}{ Kelayanan Ekonomi } & \multicolumn{1}{c}{ Kelayakan Finansial } \\
\hline NPV $: 539.850 .118$ & NPV $:-9.740 .067 .272$ \\
BCR $: 2,03$ & BCR $: 0,82$ \\
IRR $: 10,3 \%$ & IRR : 4,4\% \\
\multicolumn{1}{c}{ Kesimpulan : Layak } & PP : Tahun ke-15 \\
& \multicolumn{1}{c}{ Kesimpulan : Tidak Layak } \\
\hline
\end{tabular}

- Swasta

\begin{tabular}{|c|c|}
\hline Kelayanakan Ekonomi & Kelayakan Finansial \\
\hline NPV : 13.020 .216 .919 & NPV : 6.888.248.357 \\
\hline BCR : 63,07 & BCR : 1,31 \\
\hline IRR $: 37 \%$ & IRR : $23 \%$ \\
\hline Kesimpulan : Layak & $\begin{array}{l}\text { PP : Tahun ke-6 } \\
\text { Kesimpulan : Layak }\end{array}$ \\
\hline
\end{tabular}


- $\quad$ PCP

\begin{tabular}{|l|l|l|}
\hline Kelayakan Ekonomi & Finansial Masyarakat & Finansial Pemerintah \\
\hline NPV $: 1.609 .573 .161$ & NPV $: 6.888 .248 .357$ & NPV $: 20.588 .878 .044$ \\
BCR $: 2,48$ & BCR $: 1,31$ & BCR $: 1,39$ \\
IRR $: 61 \%$ & IRR $: 23 \%$ & IRR $: 10,6 \%$ \\
Kesimpulan Layak & PP : Tahun ke-6 & PP : Tahun ke-15 \\
& Kesimpulan : Layak & Kesimpulan : Layak \\
\hline
\end{tabular}

\section{Kesimpulan}

Kawasan perancangan yang terletak di Kelurahan Bugangan dan Rejosari memiliki karakteristik berupa kawasan permukiman yang berada di tepian sungai, melalui konsep Livable Riverfront Settlement dengan 3 indikator yang dibawanya yaitu Livable Housing Provision, Disaster Risk Management dan Job Creation diharapkan dapat menjadi kawasan permukiman tepian sungai yang layak dan nyaman bagi penghuninya. Konsep ini akan dilaksanakan melalui beberapa konsep manajemen pengelolaan, yaitu pemerintah, swasta dan PCP (Public Private Partnership) yang telah dinyatakan layak setelah dilakukan perhitungan analisis kelayakan proyeknya.

\section{Referensi}

Jaya, A. (2004). Konsep Pembangunan Berkelanjutan (Sustainable Development). Bogor.

Lennard, H. L. (1997). "Principles for the Livable City" in Lennard, S. H., S von Ungern- Sternberg, H.

L. Lennard, eds. Making Cities Livable. International Making Cities Livable Conferences.

California, USA: Gondolier Press.

Peraturan Daerah Kota Semarang Nomor 11 Tahun 2004 Tentang Rencana Detail Tata Ruang Kota RDTRK) Kota Semarang Bagian Wilayah Kota I (Kecamatan Semarang Timur) Tahun 2000-2010

Peraturan Daerah Kota Semarang Nomor 14 Tahun 2011 Tentang Rencana Tata Ruang Wilayah Kota Semarang Tahun 2011-2031

Peraturan Menteri Negara Perumahan Rakyat Nomor: 9/PERMEN/M/2008 Tentang Pedoman Bantuan Pembangunan Rumah Susun Sederhana Sewa pada Lembaga Pendidikan Tinggi dan Lembaga Pendidikan Berasrama 138

Rahmawati, A., \& Rahardjo, P. (2016). Pendekatan Kualitatif Pada Rencana Detail Tata Ruang (Studi Kasus : Kawasan Sisi Banjir Kanal Timur di Kelurahan Pulogebang). Seminar Nasional Teknologi Sains II, 56-65. Jakarta: SNTS 2016.

Shirvani, H. (1985). The Urban Design Process. New York: Van Nostrand Reinhold. Co. 